\title{
Toric Intraocular Lenses in Cataract Surgery
}

\author{
Rosa Braga-Mele, MD, MEd, FRCSC \\ Associate Professor, University of Toronto
}

\begin{abstract}
Cylindrical deficits in patients with corneal astigmatism of 0.50 diopter (D) to $1.00 \mathrm{D}$ may influence visual acuity. Increasing age and cataract surgery are correlated with greater prevalence and extent of corneal astigmatism. Conventionally, spectacles and contact lenses have been used to improve or correct corneal astigmatism. However, increasing demand for freedom from spectacles for distance vision and high prevalence of pre-existing corneal astigmatism in cataract patients have forced cataract surgery for the correction of aphakia and pre-existing corneal astigmatism to become common practice. However, implantation of toric intraocular contact lenses (IOLS) into the eye during cataract surgery may be a more predictable, powerful, and stable way of correcting pre-operative corneal astigmatism and may provide an adjunct or alternative to spectacles or relaxing incisions. Early toric IOLs were associated with post-operative rotational stability, lens misalignment, and safety concerns. The use of the new AcrySof ${ }^{\circledR}$ IQ Toric IOL for the correction of aphakia and pre-existing corneal astigmatism has largely mitigated these concerns. In addition, the AcrySof ${ }^{\circledR} I Q$ Toric IOL may also replace other treatment options for correcting pre-existing corneal astigmatism in patients undergoing cataract surgery.
\end{abstract}

\section{Keywords}

Cataract, corneal astigmatism, surgery, toric intraocular lenses

Disclosure: Rosa Braga-Mele, MD, MEd, FRCSC, is a consultant for Alcon, Allergan, and Amo.

Acknowledgment: Editorial assistance was provided by Touch Briefings.

Received: January 17, 2011 Accepted: February 28, 2011 Citation: US Ophthalmic Review, 2011;4(1):38-43 DOI: 10.17925/USOR.2011.04.01.38

Correspondence: Rosa Braga-Mele, MD, MEd, FRCSC, 200-245 Danforth Ave, Toronto, Ontario, M4K 1N2, Canada. E: rbragamele@rogers.com

Support: The publication of this article was funded by Alcon Laboratories. The views and opinions expressed are those of the author and not necessarily those of Alcon Laboratories.

In patients with corneal astigmatism, a cylindrical defect of about 0.50 diopter (D) to $1.00 \mathrm{D}$ may be considered clinically significant, and may influence visual acuity. ${ }^{1}$ It has been estimated that between 15 and $20 \%$ of patients undergoing cataract surgery have at least $1.5 \mathrm{D}$ of pre-existing corneal astigmatism. ${ }^{2}$ Increasing age is correlated with the prevalence and extent of corneal astigmatism. Up to $50 \%$ of the US population aged over 60 years has $\leq 1.00 \mathrm{D}$ of astigmatism, ${ }^{3}$ while pre-existing astigmatism exceeding $1.50 \mathrm{D}$ may be present in as many as $22 \%$ of potential cataract surgery patients. ${ }^{2,45}$ Also, with increasing age, the shift of the axis tends towards against-the-rule (ATR) astigmatism, in which the greater curvature or refractive power is in the horizontal meridian. ${ }^{6,7}$

There have been many studies evaluating astigmatism pre- and postcataract surgery. In one study undertaken to evaluate the type and the number of sutures that produce the least post-operative astigmatism, it was found that, on the whole, post-operative astigmatism tended to be of the same type or axis as pre-operatively, particularly in cases with pre-operative ATR astigmatism. There was no correlation between the amount of pre- and post-operative astigmatism, which accords with findings in another study ${ }^{8,9}$ In a study to evaluate the factors that affect post-operative astigmatism, the magnitude of the pre-operative astigmatism was found to affect the magnitude of post-operative astigmatism. This indicates that phacoemulsification incisions other than those in the steepest meridian have little modulating effect on astigmatism in patients who have a large pre-existing astigmatism. ${ }^{10}$

Conventionally, spectacles and contact lenses have been used to improve or correct pre-existing corneal astigmatism. However, there is an increasing demand for distance vision spectacle independence and, furthermore, spectacles may not always be able to provide sufficient power to correct the refractive error or can cause distortion if not aligned properly with the axis of astigmatism. Also, given the high prevalence of pre-existing corneal astigmatism in cataract patients, it has become common practice during cataract surgery to correct both aphakia and pre-existing corneal astigmatism. This may allow the opportunity to improve the accuracy of refractive correction and of uncorrected visual acuity (UCVA), thereby optimizing visual outcomes after cataract surgery.

There are multiple treatment options available for correcting pre-existing corneal astigmatism in patients undergoing cataract surgery, one of which is the use of corneal incision surgery. With this procedure, single or paired circumferential incisions, known as limbal or peripheral corneal relaxing incisions (LRIS or PCRIS, respectively), may 
be created on the steep axis of the cornea, allowing the cornea to become more rounded in shape when it heals. ${ }^{11,12}$ Nevertheless, there are concerns over the accuracy and predictability of this procedure, ${ }^{13-16}$ with the success of the process dependent upon several factors, including the skill level of the surgeon, depth and position of the cuts, variability of the healing responses, and age of the patient.

An adjunct or alternative to spectacles or the creation of relaxing incisions may be the use of toric intraocular cataract lenses (IOLS). Implantation of toric IOLs into the eye during cataract surgery may be a more predictable, powerful, and stable way of correcting pre-operative corneal astigmatism. A toric lens is one whose two surfaces differ, with one being spherical in shape and the other being toroidal. Such a shape may allow for the correction of both with-the-rule (WTR) and ATR astigmatism depending on placement of the toroidal axis. ${ }^{17}$ Furthermore, toric IOL implantation may be a more effective and predictable treatment option than the creation of relaxing incisions since the former does not require any special surgical skills or instrumentation and tends to be more stable over time.

\section{The Use of Toric Intraocular Lenses to Correct Astigmatism in Cataract Patients}

The efficacy and safety of toric IOL implantation for correcting pre-existing corneal astigmatism in patients undergoing cataract surgery has been demonstrated in several studies. ${ }^{16-21}$ Particularly, in a retrospective study that compared toric IOLS with spherical IOLS plus LRIS, ${ }^{18}$ a greater proportion of eyes in the toric IOL group versus the spherical IOL group had achieved $20 / 40$ or better UCVA (84 versus 76\%) at three months post-operation. Furthermore, although the pre-operative mean refractive cylinder was similar in both groups, there was a substantially greater proportion of patients in the toric IOL group versus the spherical IOL group who achieved a post-operative refractive cylinder of less than or equal to $0.75 \mathrm{D}$ (55.4 versus $21.5 \%$, respectively).

Currently, there are two types of toric IOLS available in the US: the Staar ${ }^{\circledR}$ Toric IOL (Staar Surgical, Monrovia, CA) and the AcrySof ${ }^{\circledR}$ IQ Toric IOL SN6ATT series (Alcon Laboratories, Inc., Fort Worth, TX). These toric IOLS are intended for the correction of aphakia and pre-existing corneal astigmatism. This article will discuss the characteristics, effectiveness, and safety of the AcrySof ${ }^{\circledR}$ IQ Toric IOL for correcting pre-existing corneal astigmatism in patients undergoing cataract surgery.

\section{Characteristics of the AcrySof ${ }^{\circledR}$ IQ Toric Intraocular Lens}

The physical characteristics of the AcrySof ${ }^{\circledR}$ IQ Toric IOL are listed in Table $1 .{ }^{22}$ AcrySof ${ }^{\circledR}$ IQ Toric IOL has a high refractive index and it can offer various IOL cylinder powers depending on the model used: 1.50D, 2.25D, and 3.00D. The toric IOL has ultraviolet (UV) and blue light filtering properties, with the latter approximating the way in which the human lens filters the $400-475 \mathrm{~nm}$ blue light wavelength range. The lens has a single-piece aspherical design, with the anterior surface designed with negative spherical aberration to compensate for the positive spherical aberration of the average cornea (see Figure 1). The lens itself is composed of a soft acrylic material, which means that the lens can be folded prior to insertion into the posterior chamber of the eye through a
Table 1: The Physical Characteristics of the AcrySof ${ }^{\circledR}$ IQ Toric Intraocular Lens

\begin{tabular}{|c|c|c|}
\hline \multirow[t]{2}{*}{ Characteristics } & Model & SN6AT5 \\
\hline & \multicolumn{2}{|c|}{ Collectively Referred to as Model SN6ATT } \\
\hline Optic type & \multicolumn{2}{|c|}{ Bioconvex toric aspheric optic } \\
\hline Optic/haptic material & \multicolumn{2}{|c|}{$\begin{array}{c}\text { Ultraviolet and blue light filtering } \\
\text { Acrylate/methacrylate copolmer ultraviolet } \\
\text { cut-off at } 10 \% \text { T:402nm* }\end{array}$} \\
\hline $\begin{array}{l}\text { IOL powers (spherical } \\
\text { equivalent diopters) }\end{array}$ & \multicolumn{2}{|c|}{$\begin{array}{l}\text { For available power range see } \\
\text { Alcon product guide }\end{array}$} \\
\hline $\begin{array}{l}\text { IOL cylinder power } \\
\text { (diopters) }\end{array}$ & 2.25 & 3.00 \\
\hline Index of refraction & 1.55 & \\
\hline Haptic configuration & Stableforce & \\
\hline Optic diameter (mm) & 6.0 & \\
\hline Overall length (mm) & 13.0 & \\
\hline Haptic angle & $0^{\circ}$ & \\
\hline
\end{tabular}

*The effects of this aspheric design feature have been clinically assessed on the AcrySof ${ }^{\circledR} I Q$ IOL Model SN6OWF. Adapted from AcrySof IQ Toric IOL Product Information (Alcon, 2009). ${ }^{22}$ $I O L=$ intraocular lens.

Figure 1: The Asymmetric Shape of the AcrySof ${ }^{\circledR}$ IQ Toric Intraocular Lens
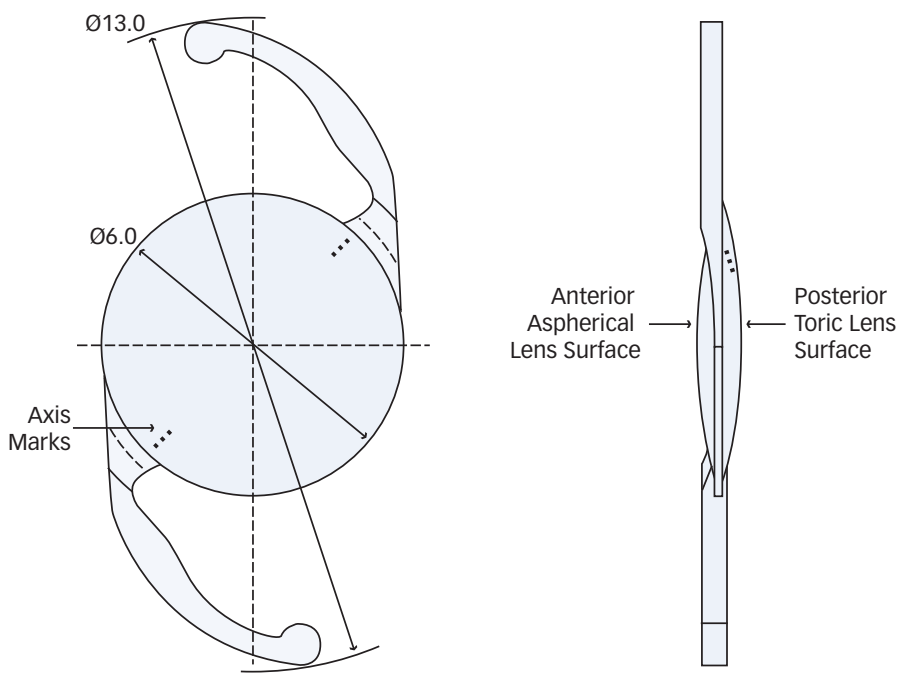

All dimensions are in millimeters. Adapted from Acrysof ${ }^{\circledR}$ IQ Toric IOL Product Information (Alcon, 2009). ${ }^{22}$

Table 2: Rotational Stability of the AcrySof ${ }^{\circledR}$ IQ Toric Intraocular Lens

\begin{tabular}{|c|c|c|c|c|c|}
\hline \multirow[b]{2}{*}{ Parameter } & \multicolumn{5}{|c|}{ Post-operative Assessment } \\
\hline & 1 Day & 1 Month & 3 Months & 6 Months & $\begin{array}{l}\text { Last Carried } \\
\text { Forward* }\end{array}$ \\
\hline $\begin{array}{l}\text { Mean degrees from } \\
\text { operative axis }\end{array}$ & $2 \pm 3$ & $2 \pm 4$ & $2 \pm 3$ & $2 \pm 2$ & $2 \pm 3$ \\
\hline $\begin{array}{l}\text { Mean degrees from } \\
\text { one-day post-op axis }\end{array}$ & - & $2 \pm 4$ & $1 \pm 2$ & $1 \pm 2$ & $2 \pm 4$ \\
\hline IOL assessed (n) & 212 & 217 & 188 & 161 & 217 \\
\hline
\end{tabular}

* Last post-operative observation for each eye was carried forward and then final results were averaged. Means \pm standard deviation. $I O L=$ intraocular lens.

Adapted from Ahmed II, Rocha G, Slomovic AR, et al., Visual function and patient experience after bilateral implantation of toric intraocular lenses, J Cataract Refract Surg, 2010,36:609-16. ${ }^{26}$ 
Figure 2: Magnitude of Astigmatism in 164 Eyes Pre- and Post-operatively

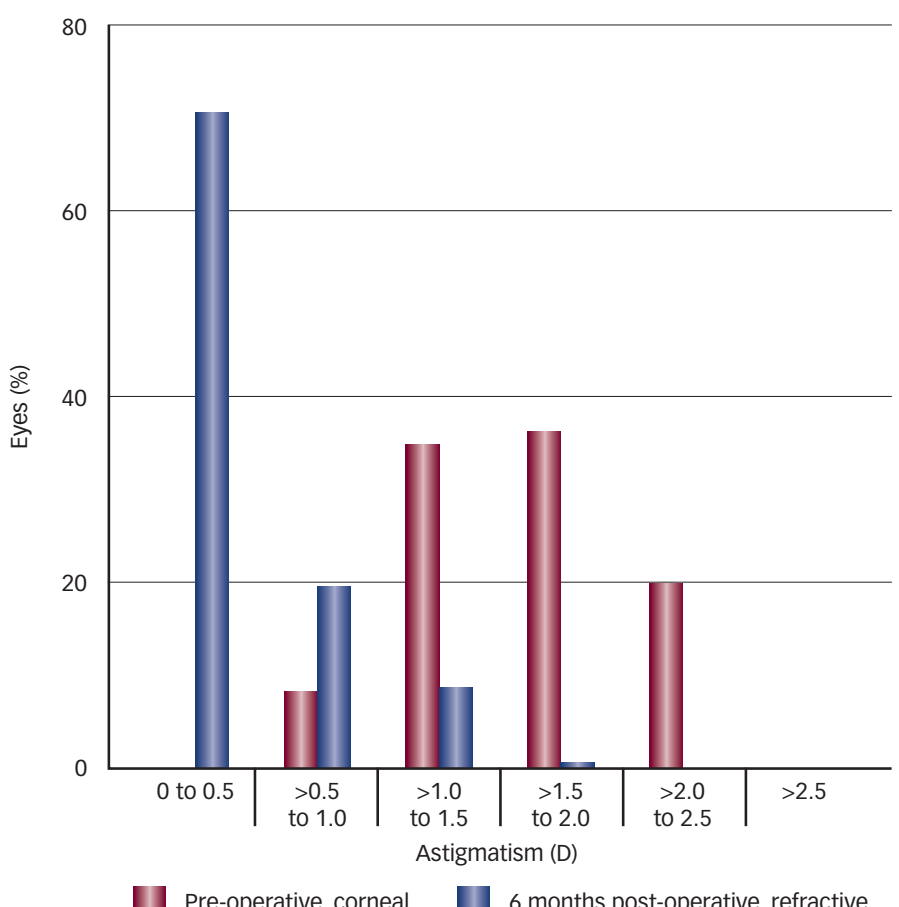

Adapted from Ahmed II, Rocha G, Slomovic AR, et al., Visual function and patient experience after bilateral implantation of toric intraocular lenses, J Cataract Refract surg, $2010 ; 36: 609-16 .^{26}$

Figure 3: Spectacle Use for Distance Vision Pre- and Post-operatively in 78 Patients

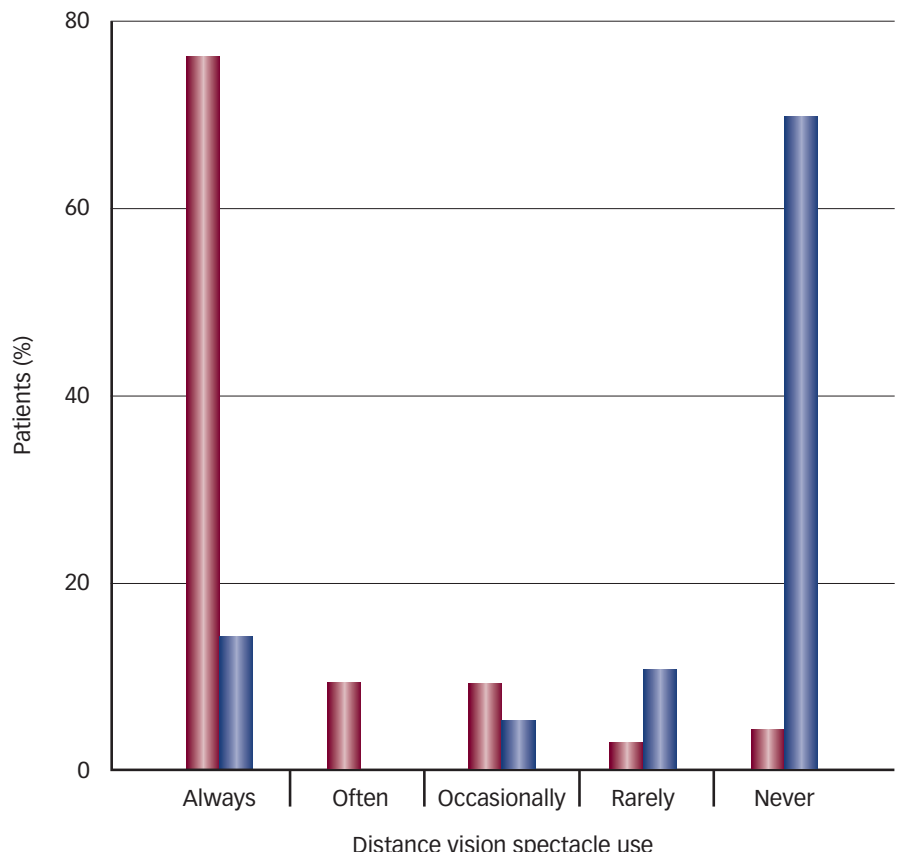

11 Pre-operative 6 months post-operative

Adapted from Ahmed II, Rocha G, Slomovic AR, et al., Visual function and patient experience after bilateral implantation of toric intraocular lenses, J Cataract Refract Surg, 2010;36:609-16. ${ }^{26}$ small corneal incision, which is currently $2.2 \mathrm{~mm}$ with a D cartridge and the MONARCH ${ }^{\circledR}$ inserter. ${ }^{23}$ Once inserted into the eye, the lens unfolds to its original size. In a study to compare the AcrySof ${ }^{\circledR}$ Toric IOL implantation with paired opposite clear corneal incisions for astigmatism correction in patients having cataract surgery, better contrast sensitivity was obtained in the toric IOL group at high spatial frequencies under both photopic and mesopic conditions. ${ }^{21}$

Rotational Stability and Predictability of the AcrySof ${ }^{\circledR}$ Toric Intraocular Lens in Pseudophakia

Pseudophakia is the presence of an artificial lens in the eye following cataract surgery. Centration and stability of any IOL is essential for good visual outcomes. For toric IOLS, accurate alignment is critical in compensating for corneal cylinder and thus producing good UCVA. Post-operative IOL rotation may lead to IOL misalignment or misplacement. It is estimated that there may be an average loss of corneal cylinder power of approximately $3 \%$ every time the lens rotates by one degree away from the intended axis, while there may be no astigmatic correction if the IOL rotates 30 degrees or more. ${ }^{24,25}$

While there were concerns about post-operative rotation with the earlier versions of toric IOLS, this problem has been substantially reduced with the AcrySof ${ }^{\circledR}$ Toric IOL. Greater rotational stability facilitates accurate IOL placement and, hence, more predictable visual outcomes. Table 2 demonstrates data for the rotational stability of the Acrysof ${ }^{\circledR} I O L$, assessed post-operatively in a prospective study where patients with cataract and pre-existing corneal astigmatism from 1.00 to $2.50 \mathrm{D}$ were implanted with bilateral AcrySof ${ }^{\circledR}$ Toric IOLs. ${ }^{26}$

In another study comparing the early rotational stability of two toric IOLs, the mean IOL rotation was significantly lower with the AcrySof ${ }^{\circledR}$ Toric IOL versus an earlier IOL, AA4203 group $\left(3.35 \pm 3.41^{\circ}\right.$ versus $5.56 \pm 8.49^{\circ}$, respectively; $p=0.0232) .{ }^{20}$ Additionally, more IOLs in the AcrySof ${ }^{\circledR}$ IOL group were aligned at or within 5,10 , and $15^{\circ}$ when compared with IOLS in the AA4203 group $\left(90,99\right.$, and $100 \%$ for the Acrysof ${ }^{\circledR}$ IOL group versus 70, 90, and 97\% for the AA4203 group, respectively).

In a further single-center prospective clinical trial of the AcrySof ${ }^{\circledR}$ Toric $\mathrm{IOL}$, the results showed a mean misalignment of $3.5^{\circ}$, with no eye having a misalignment greater than $10^{\circ}$. In another study to assess the rotational stability of the AcrySof ${ }^{\circledR}$ Toric IOL during the first six post-operative months, the mean post-operative IOL rotation was slight: $2.44 \pm 1.84^{\circ}$ at one month and $2.66 \pm 1.99^{\circ}$ at six months. These results compare well with those in the above studies of the AcrySof ${ }^{\circledR}$ Toric IOL and with findings in the US Food and Drug Administration (FDA) trial, which reported a mean rotation of less than $4^{0} .18,27,28$

Finally, a study to report the clinical results of AcrySof ${ }^{\circledR}$ Toric IOL implantation for pre-existing astigmatism correction compared the rotation of the IOLS one and six months post-operatively. UCVA was found to be $\geq 0.5$ in 26 of 29 eyes (89.7\%) and $\geq 0.8$ in 19 of 29 eyes (65.5\%). One month post-operation, the mean toric IOL axis rotation was $2.2 \pm 1.5^{\circ}$ (range $0.6-7.8^{\circ}$ ). Six months post-surgery, the mean toric IOL axis rotation was $2.7 \pm 1.5^{\circ}$ (range $0.9-8.4^{\circ}$ ). The later rotation was found to be more than one degree $\left(1.1^{\circ}\right)$ only in one eye $(3 \%)$, and in every other occurrence was less than this value, and increased between one 
Figure 4: Vision Satisfaction Ratings Pre- and Post-operatively

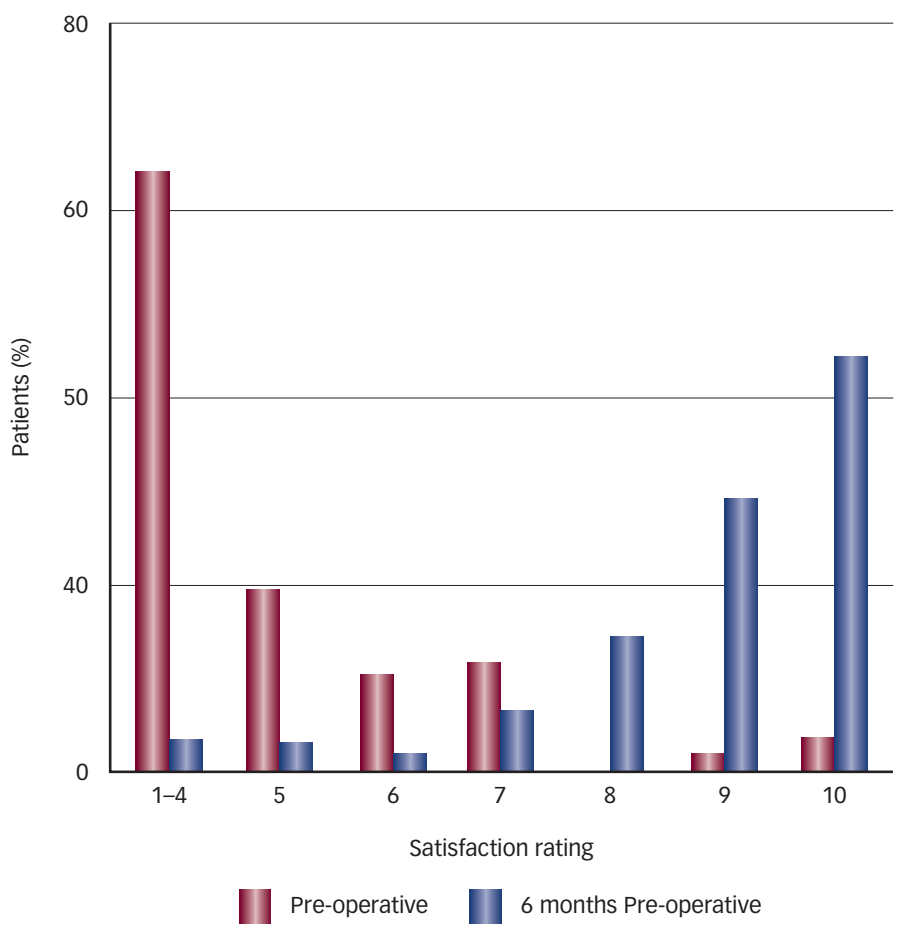

Rating scale: 1 = completely unsatisfied; 10 = completely satisfied. Adapted from Ahmed II, Rocha G, Slomovic AR, et al., Visual function and patient experience after bilateral implantation of toric intraocular lenses, J Cataract Refract Surg, 2010;36:609-16. ${ }^{26}$

and six months. No eye had secondary surgery to relocate the IOL axis during the six-month post-operative phase, while no patient experienced any significant IOL rotation $\left(>10^{\circ}\right) .{ }^{29}$ Thus, the AcrySof ${ }^{\circledR}$ Toric IOL has been proved to have excellent immediate and long-term rotational stability, thereby offering good visual outcomes.

Efficacy and Safety of Acrysof ${ }^{\circledR}$ Toric Intraocular Lens Implantation in Patients Undergoing Surgery

The efficacy and safety of AcrySof ${ }^{\circledR}$ Toric IOL implantation for correcting pre-existing corneal astigmatism in patients undergoing cataract surgery have been evaluated in a number of clinical trials. ${ }^{17,18,20,21,26}$

In a single-center prospective trial, 53 cataract eyes (43 patients) were implanted with an AcrySof ${ }^{\circledR}$ Toric IOL. ${ }^{18}$ Four months post-operatively, residual refractive astigmatism of less than 0.75 D was achieved in $74 \%$ of eyes while $91 \%$ of the eyes achieved a value of less than $1.00 \mathrm{D}$. Overall, more than $90 \%$ of the eyes achieved a UCVA of $20 / 40$ or better, while a UCVA of $20 / 25$ or better was achieved by almost $80 \%$. In a prospective study by Ahmed et al., ${ }^{26}$ patients with cataract and pre-existing corneal astigmatism (from 1.00 to 2.50D) underwent bilateral AcrySof ${ }^{\circledR}$ Toric IOL implantation. Of the 117 patients (234 eyes), $99 \%$ achieved a binocular UCVA of $20 / 40$ or better while $63 \%$ achieved $20 / 20$ or better. Referring to Figure 2, it is evident that a substantial number of eyes achieved a reduction in the magnitude of astigmatism six months post-operatively versus pre-operatively. Of the 164 eyes for which data are available, $90.2 \%$ of the eyes had $\leq 1.00 \mathrm{D}$ of residual refractive astigmatism post-operatively while only about 7-8\%
Figure 5: Patient-reported Need for Distance Spectacles Pre-operatively and Three Months Post-operatively
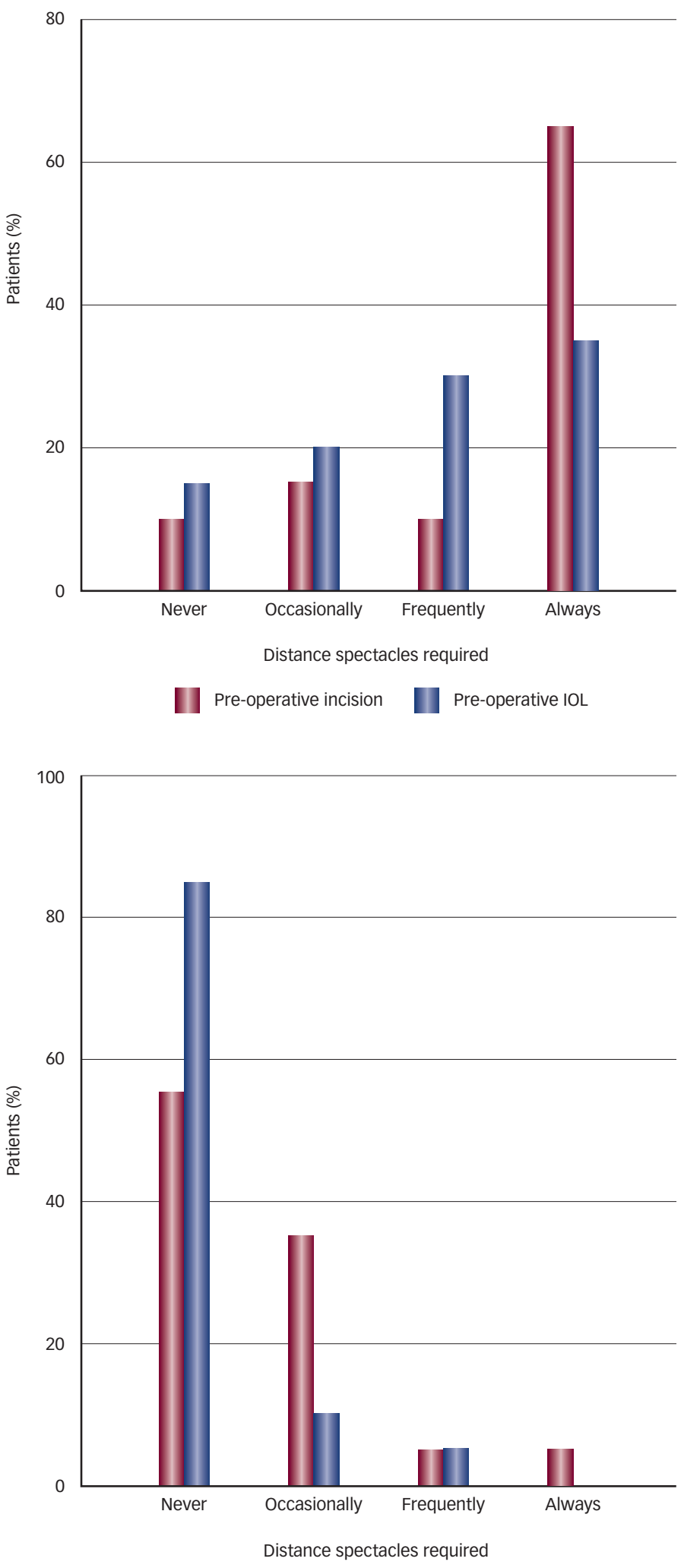

11 months post-operative incision

3 months post-operative IOL

Adapted from Ahmed II, Rocha G, Slomovic AR, et al., Visual function and patient experience after bilateral implantation of toric intraocular lenses, J Cataract Refract Surg, 2010;36:609-16.20 IOL = intraocular lens. 
of the eyes had $\leq 1.00 \mathrm{D}$ of refractive astigmatism pre-operatively. A paired $t$ test found the mean residual refractive astigmatism of $0.4 \pm 0.4 \mathrm{D}$ to be significantly lower $(p<0.001)$ than pre-operative corneal values. In terms of safety, the toric IOLs were reported to be safe, with there being a significant reduction in the frequency and severity of halos and glares from pre- to post-operative assessment $(p<0.05)$.

It has been earlier noted in this article that there is an increasing demand for distance vision spectacle independence from patients. Therefore, the effectiveness of new treatment options for corneal astigmatism should be evaluated in terms of whether they improve patient-reported outcomes such as distance vision spectacle independence and patient satisfaction. In the above-mentioned study by Ahmed et al.,. 78 patients were asked to complete a subjective questionnaire pre-operatively and six months post-operatively (see Figure 3). Importantly, the proportion of patients reported to be spectacle independent for distance vision was significantly greater six months post-operatively versus pre-operatively $(p<0.001)$. While only around $4 \%$ of the patients pre-operatively reported never having to use spectacles for distance vision, this value rose to nearly $70 \%$ six months post-operatively. In this study, a rating scale $(1=$ completely unsatisfied; $10=$ completely satisfied) was used to evaluate satisfaction with vision of 77 patients six months post-operatively. The results showed $93.5 \%$ rated their post-operative satisfaction as 7 or higher, while $72.7 \%$ of the patients rated their satisfaction as 9 or 10 (see Figure 4). A paired $t$ test found patient satisfaction with vision to be significantly greater $(p<0.001)$ six months post-operatively when compared with the values at baseline.

Another study assessed astigmatic reduction and rotational stability in the early post-operative period and at long-term follow-up of the AcrySof ${ }^{\circledR}$ Toric IOL in a series of cataract surgery patients with corneal astigmatism greater than 1.0D. This study included 30 eyes from 24 consecutive patients who underwent implantation of an AcrySof ${ }^{\circledR}$ Toric IOL. At final follow-up at a mean of 13.3 months, $73.3 \%$ of eyes showed $20 / 25$ or better UCVA. The mean change in keratometric astigmatism was $0.18 \pm 0.39 \mathrm{D}$ and corneal astigmatism did not significantly change post-operatively $(p=0.360)$. At final follow-up, the mean refractive cylinder was $-0.28 \pm 0.38 \mathrm{D}$ from $-1.28 \pm 0.48 \mathrm{D}$. The mean rotation of the toric IOLS was $3.45 \pm 3.39^{\circ}$ at final follow-up. One eye (3.3\%) had IOL rotation of $10.3^{\circ}$, and the remaining eyes (96.7\%) had rotations of less than $10^{\circ} .{ }^{23}$

The clinical and patient-reported outcomes of bilateral AcrySof ${ }^{\circledR}$ IQ Toric IOL implantation have also been compared with AcrySof ${ }^{\circledR}$ spherical IOL implantation. ${ }^{30} \mathrm{~A}$ total of 62 patients were implanted with either the toric or the spherical IOL and, six months post-operatively, patients with toric IOLs were noted to have significantly less residual refractive cylinder $(p<0.0001)$ and better binocular UCVA versus those with spherical control IOLS $(p=0.0014)$. A significantly greater proportion of patients with toric IOL implantation achieved spectacle independence for distance vision versus the spherical IOL group and did not require prescription glasses for near or distance vision $(\mathrm{p}=0.0190)$. A similar result has been observed in a multicenter, randomized, subject-masked study involving 517 patients with cataracts and pre-existing corneal astigmatism. The uncorrected distance visual acuity of 20/20 or better with an AcrySof ${ }^{\circledR}$ Toric IOL was significantly improved $(40.7 \%)$ compared with the control $(19.4 \%)(p<0.05)$. Six months after surgery, $61.0 \%$ of subjects with the Acrysof ${ }^{\circledR}$ IQ Toric IOL reported spectacle independence for distance vision compared with $36.4 \%$ of those with the control IOL $(p<0.0001)$. With both lenses, adverse events were few and were as expected in cataract surgery. ${ }^{31}$

Finally, a prospective randomized comparative case series has compared implantation of toric IOLS to spherical IOLS with PCRIS for the management of astigmatism during phacoemulsification in eyes with cataract and corneal astigmatism (1.00-3.00D). ${ }^{32}$ Three months post-operatively, the mean UCVA in the toric IOL group and the PCRI group were $0.13 \pm 0.10$ and $0.19 \pm 0.12$, respectively. There was a significant reduction $(p<0.01)$ in the mean residual refractive cylinder in both groups (toric IOL: 0.61 $\pm 0.41 \mathrm{D}$; PCRI: $1.32 \pm 0.60 \mathrm{D}$ ). Importantly, there was a significantly lower residual refractive cylinder in the toric IOL group versus the PCRI group $(p<0.01)$. Additionally, there was a trend toward better mesopic contrast sensitivity with glare in the toric IOL group. Distance vision spectacle use pre-operatively in the toric IOL and PCRI group was $85 \%(n=17)$ and $80 \%(n=18)$, respectively. Post-operatively, these values decreased to $15 \%$ and $45 \%$, respectively, indicating that while distance vision spectacle use decreased in both groups, distance vision spectacle independence was significantly greater in the toric IOL group. The greater distance vision spectacle independence in the toric IOL may be attributed to the greater effectiveness and predictability of toric IOL implantation when compared with PCRIs (see Figure 5).

\section{Cost to Benefit Ratio of the AcrySof ${ }^{\circledR}$ IQ Toric Intraocular Lens in Pseudophakia}

Cataract surgery and subsequent implantation of an artificial IOL can be a costly procedure and therefore it is important to consider the cost/benefit ratio of the procedures before carrying them out. Using an analytical model of hypothetical patients with pre-existing astigmatism, a study evaluated the economic value of improved UCVA among patients with cataract and pre-existing astigmatism (1.5-3.0D) who were treated with toric IOLs compared with conventional monofocal IOLS (with or without intra-operative refractive correction, $\mathbf{I R C}){ }^{33}$ There were higher first-year costs for the toric IOL $(\$ 5,739)$ versus the conventional IOL with $(\$ 5,635)$ or without $(\$ 4,687)$ IRC. However, these were offset by lifetime cost savings of $\$ 34$ per patient, with $\$ 393$ per patient achieving UCVA of 20/25 or better, and $\$ 349$ per quality-adjusted life year versus the conventional IOL without IRC. It was alluded to that this lifetime cost saving with toric IOL versus conventional IOL may be partly due to the reduced spectacle dependence of the former group: $67 \%$ of the patients receiving toric IOL achieved distance vision spectacle independence compared with conventional IOLs with (63\%) or without IRC (53\%).

\section{Conclusion}

While early toric IOLs were associated with concerns over post-operative rotational stability and, consequently, lens misalignment, these concerns have largely been mitigated with the new AcrySof ${ }^{\circledR}$ IQ Toric IOL. The safety, efficacy, and predictability of AcrySof ${ }^{\circledR}$ IQ Toric IOL implantation 
for the correction of aphakia and pre-existing corneal astigmatism in cataract patients have been demonstrated by several previously noted clinical trials. Post-operatively, there was a significant number of cataract surgery patients who were distance vision spectacle independent and satisfied with their vision, and a large number that achieved greater than 20/40 UCVA. This toric IOL may serve as an adjunct or alternative to other treatment options for correcting pre-existing corneal astigmatism in patients undergoing cataract surgery.
1. Nanavaty MA, Vasavada AR, Patel AS, et al., Analysis of patients with good uncorrected distance and near vision after monofocal intraocular lens implantation, 1 Cataract Refract surg 2006:32:1091-7.

2. Hoffer KJ, Biometry of 7,500 cataractous eyes, Am J Ophthalmol 1980;90:360-8.

3. Vitale S, Ellwein L, Cotch MF, et al., Prevalence of refractive error in the United States, 1999-2004, Arch Ophthalmol, 2008:126:1111-9.

4. Ferrer-Blasco T, Montes-Mico R, Peixoto-de-Matos SC, et al., Prevalence of corneal astigmatism before cataract surgery, $J$ Cataract Refract Surg, 2009;35:70-5.

5. Ninn-Pedersen K, Stenevi U, Ehinger B, Cataract patients in a defined Swedish population 1986-1990. II. Preoperative observations, Acta Ophthalmol (Copenh), 1994:72:10-5.

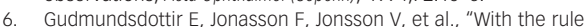
astigmatism is not the rule in the elderly. Reykjavik Eye Study: population based study of refraction and visual acuity in citizens of Reykjavik 50 years and older. Iceland-Japan Co-Working Study Groups, Acta Ophthalmol Scand, 2000;78:642-6.

7. Jonasson $\mathrm{F}$, Thordarson $\mathrm{K}$, Ophthalmic services for 0-49 year old Icelanders: preponderance of female attendance, Acta Ophthalmol Suppl, 1990;69:99-103.

8. Beasley $\mathrm{H}$, Keratometric changes after cataract surgery, Trans Am Ophthalmol Soc, 1967;65:168-88.

9. Singh D, Kumar K, Keratometric changes after cataract extraction, Br J Ophthalmol, 1976;60:638-41.

10. Cho YK, Kim MS, Perioperative modulating factors on astigmatism in sutured cataract surgery, Korean $\mathrm{J}$ Ophthalmol 2009:23:240-8.

11. Budak K, Friedman NJ, Koch DD, Limbal relaxing incisions with cataract surgery, I Cataract Refract Surg, 1998;24:503-8.

12. Muller-Jensen $\mathrm{K}$, Fischer $\mathrm{P}$, Siepe $U$, Limbal relaxing incisions to correct astigmatism in clear corneal cataract surgery, I Refract Surg, 1999:15:586-9.

13. Budak K, Yilmaz G, Aslan BS, et al., Limbal relaxing incisions in congenital astigmatism: 6 month follow-up, I Cataract Refract Surg, 2001;27:715-9

14. Carvalho MJ, Suzuki SH, Freitas LL, et al., Limbal relaxing incisions to correct corneal astigmatism during phacoemulsification, J Refract Surg, 2007:23:499-504.

15. Nichamin LD, Astigmatism control, Ophthalmol Clin North Am, 2006;19:485-93.

16. Sun $\mathrm{XY}$, Vicary $\mathrm{D}$, Montgomery $\mathrm{P}$, et al., Toric intraocular lense for correcting astigmatism in 130 eyes, Ophthalmology, 2000;107:1776-81, discussion 81-2.

17. Mendicute J, Irigoyen C, Aramberri J, et al., Foldable toric intraocular lens for astigmatism correction in cataract patients, 1 Cataract Refract Surg, 2008:34:601-7.

18. Bauer NJ, de Vries NE, Webers CA, et al., Astigmatism management in cataract surgery with the Acrysof toric intraocular lens, I Cataract Refract Surg, 2008;34:1483-8.

19. Chang DF, Early rotational stability of the longer Staar toric intraocular lens: fifty consecutive cases, I Cataract Refract surg, 2003:29:935-40.

20. Chang DF, Comparative rotational stability of single-piece open-loop acrylic and plate-haptic silicone toric intraocular lenses, I Cataract Refract Surg, 2008;34:1842-7.

21. Mendicute J, Irigoyen C, Ruiz M, et al., Toric intraocular lens versus opposite clear corneal incisions to correct astigmatism in eyes having cataract surgery, 1 Cataract Refract Surg, 2009;35:451-8

22. Alcon, Acrysof IQ Toric Astigmatism IOL Product Information, 2009.

23. Kim MH, Chung TY, Chung ES, Long-term efficacy and rotational stability of AcrySof toric intraocular lens implantation in cataract surgery, Korean J Ophthalmol, 2010:24:207-12.
24. Ma JJ, Tseng SS, Simple method for accurate alignment in toric phakic and aphakic intraocular lens implantation, Cataract Refract Surg, 2008;34:1631-6.

25. Shimizu K, Misawa A, Suzuki Y, Toric intraocular lenses: correcting astigmatism while controlling axis shift, I Cataract Refract Surg, 1994;20:523-6.

26. Ahmed II, Rocha G, Slomovic AR, et al., Visual function and patient experience after bilateral implantation of toric intraocular lenses, I Cataract Refract Surg, 2010:36:609-16.

27. Horn JD, Status of toric intraocular lenses, Curr Opin Ophthalmol, 2007;18:58-61.

28. Koshy JJ, Nishi $\mathrm{Y}$, Hirnschall $\mathrm{N}$, et al., Rotational stability of a single-piece toric acrylic intraocular lens, I Cataract Refract Surg, 2010;36:1665-70.

29. Tsinopoulos IT, Tsaousis KT, Tsakpinis D, et al., Acrylic toric intraocular lens implantation: a single center experience concerning clinical outcomes and postoperative rotation, Clin Ophthalmol, 2010;4:137-42.

30. Lane SS, Ernest P, Miller KM, et al., Comparison of clinical and patient-reported outcomes with bilateral AcrySof toric or spherical control intraocular lenses, J Refract Surg, 2009:25:899-901.

31. Holland $\mathrm{E}$, Lane $\mathrm{S}$, Horn JD, et al., The AcrySof Toric intraocular lens in subjects with cataracts and corneal astigmatism: a randomized, subject-masked, parallel-group, 1-year study Ophthalmology, 2010;117:2104-11.

32. Mingo-Botin D, Munoz-Negrete FJ, Won Kim HR, et al., Comparison of toric intraocular lenses and peripheral corneal relaxing incisions to treat astigmatism during cataract surgery, I Cataract Refract Surg, 2010;36:1700-8.

33. Pineda R, Denevich S, Lee WC, et al., Economic evaluation of toric intraocular lens: a short- and long-term decision analytic model, Arch Ophthalmol, 2010;128:834-40. 